\title{
The SAVE RITA trial at 5 years: More evidence is needed to transform a vein to an artery
}

\author{
Mario Gaudino, MD, ${ }^{\mathrm{a}}$ and Stephen E. Fremes, $\mathrm{MD}^{\mathrm{b}}$ \\ From the ${ }^{\mathrm{a} D e p a r t m e n t}$ of Cardiothoracic Surgery, Weill Cornell Medical College, New York, NY; and the ${ }^{\mathrm{b}}$ Divi- \\ sion of Cardiac Surgery, Schulich Heart Centre, Department of Surgery, Sunnybrook Health Sciences Centre, \\ University of Toronto, Toronto, Ontario, Canada. \\ Disclosures: Authors have nothing to disclose with regard to commercial support. \\ Received for publication April 25, 2018; accepted for publication April 25, 2018; available ahead of print June 5, \\ 2018. \\ Address for reprints: Mario Gaudino, MD, Department of Cardiothoracic Surgery, Weill Cornell Medicine $525 \mathrm{E}$ \\ 68th St, New York, NY 10065 (E-mail: mfg9004@med.cornell.edu). \\ J Thorac Cardiovasc Surg 2018;156:1434-5 \\ $0022-5223 / \$ 36.00$ \\ Copyright $(2018$ by The American Association for Thoracic Surgery \\ https://doi.org/10.1016/j.jtcvs.2018.04.103
}

In this issue of The Journal of Thoracic and Cardiovascular Surgery, Kim and colleagues ${ }^{1}$ report the angiographic results of the Saphenous Vein Versus Right Internal Thoracic Artery as a Y-Composite Graft (SAVE RITA) trial at 5 years. Kim and colleagues ${ }^{1}$ are to be commended for carrying out an angiographic randomized trial with excellent midterm follow-up.

The study was conceived with the aim of evaluating the hypothesis that saphenous vein (SV) grafts are noninferior to right internal thoracic artery grafts when used as a $\mathrm{Y}$ composite proximally anastomosed to the left internal thoracic artery (LITA) graft. The SV grafts were not manually distended but were allowed to dilate when exposed to arterial pressure. The SAVE RITA trial proposes that as the SV is anastomosed to the proximal part of the LITA, vascular mediators produced by the artery can protect the vein from development of atherosclerosis. In addition, the $\mathrm{SV}$ is exposed to a different pattern of circulatory stress than when attached directly to the aorta. It is of note, however, that the site of proximal anastomosis (aorta vs LITA) has been shown not to affect the patency rate of other conduits, such as the radial artery and the right internal thoracic artery itself. $^{2,3}$ Another key aspect of the trial is that all patients underwent an off-pump, no-touch, anaortic operation. Revascularization performed without aortic manipulation has been reported to be associated with fewer cerebral events. 4

The SAVE RITA trial was planned as a noninferiority trial, with what we consider to be a large noninferiority margin of $8 \%$. A smaller, more clinically acceptable difference would have required a larger sample size. In fact, similar trials aimed at assessing the difference in patency between an arterial and a venous conduit had much larger sample sizes. ${ }^{5,6}$ In addition, Kim and colleagues ${ }^{1}$ analyzed the patency data such that the unit of analysis was the distal anastomosis, with the assumption that the anastomoses are independent of one another. This is clearly false, because

\section{References} 1424-33.e1.

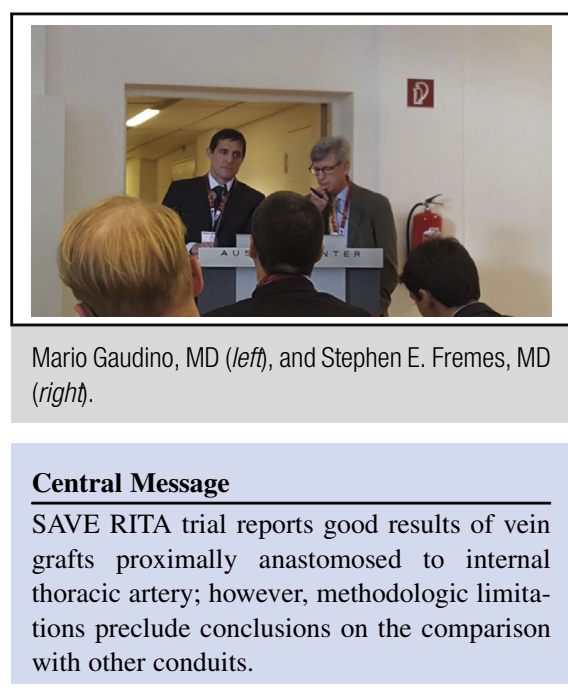

See Article page 1424.

grafts within each patient have 2 levels of dependence-1 at the patient level and another at the graft level (because all grafts were composite and sequential). A more conservative statistical approach would have required a larger sample size as well. Finally, with 186 subjects, this analysis is clearly largely underpowered to detect even large differences in clinical events, and the study therefore must be viewed as purely descriptive in this regard.

In conclusion, the 5-year analysis of the SAVE RITA is a nice description of the midterm patency rate of SV grafts proximally anastomosed to the LITA. The use of a systematic anaortic technique is commendable. Arteriovenous composite grafting remains a bail-out option for most surgeons. This study suggests that very good results can be achieved when a minimally manipulated SV graft is used, although the use of SV extensions should be avoided. Replication of these results in larger studies and longer clinical and angiographic follow-up of the SAVE RITA patients are obviously needed before wider adoption is recommended for patients with other grafting options.

1. Kim M-S, Hwang HY, Kim JS, Oh SJ, Jang M-J, Kim K-B. Saphenous vein versus right internal thoracic artery as a Y-composite graft: Five-year angiographic and clinical results of a randomized trial. J Thorac Cardiovasc Surg. 2018;156:

2. Gaudino M, Alessandrini F, Pragliola C, Cellini C, Glieca F, Luciani N, et al. Effect of target artery location and severity of stenosis on mid-term patency of aorta-anastomosed vs. internal thoracic artery-anastomosed radial artery grafts. Eur J Cardiothorac Surg. 2004;25:424-8. 
3. Glineur D, Boodhwani M, Hanet C, de Kerchove L, Navarra E, Astarci P, et al. Bilateral internal thoracic artery configuration for coronary artery bypass surgery: a prospective randomized trial. Circ Cardiovasc Interv. 2016;9.

4. Zhao DF, Edelman JJ, Seco M, Bannon PG, Wilson MK, Byrom MJ, et al. Coronary artery bypass grafting with and without manipulation of the ascending aorta: a network meta-analysis. J Am Coll Cardiol. 2017;69:924-36.
5. Desai ND, Cohen EA, Naylor CD, Fremes SE. Radial Artery Patency Study Investigators. A randomized comparison of radial-artery and saphenous-vein coronary bypass grafts. $N$ Engl J Med. 2004;351:2302-9.

6. Goldman S, Sethi GK, Holman W, Thai H, McFalls E, Ward HB, et al. Radial artery grafts vs saphenous vein grafts in coronary artery bypass surgery: a randomized trial. JAMA. 2011;305:167-74. 